\title{
A Conceptual Framework for Gamified Learning Management System for LINUS Students
}

\author{
Syadiah Nor Wan Shamsuddin, Muhammad Faisal Selman, Ismahafezi Ismail, Maizan Mat Amin, \\ Norkhairani Abdul Rawi \\ Faculty of Informatics and Computing, Universiti Sultan Zainal Abidin, Malaysia
}

\begin{tabular}{|c|c|}
\hline Article Info & ABSTRACT \\
\hline Article history: & Gamification is a term that refers to the use of game elements in non-game \\
\hline Received Sep 13, 2018 & motivate and engage learners in a variety of tasks. LINUS program is \\
\hline Revised Oct 25, 2018 & intended to ensure that all students from standard one are able to master the \\
\hline Accepted Nov 1, 2018 & $\begin{array}{l}\text { basics of reading, writing and counting at the end of standard three. } \\
\text { Gamification will help as a learning tool to assist with the learning process }\end{array}$ \\
\hline Keywords: & the aim of this paper is to propose a framework of Gamified Learning \\
\hline Gamification & Management System for Linus students. This framework consists of \\
\hline Gamified & theory that construct gamified learning management system. \\
\hline Learning Management System & \\
\hline LINUS & \\
\hline Motivation & $\begin{array}{r}\text { Copyright }(\odot 2018 \text { Institute of Advanced Engineering and Science. } \\
\text { All rights reserved. }\end{array}$ \\
\hline \multicolumn{2}{|l|}{ Corresponding Author: } \\
\hline \multicolumn{2}{|c|}{$\begin{array}{l}\text { Syadiah Nor Wan Shamsuddin, } \\
\text { Faculty of Informatics and Computing, } \\
\text { Universiti Sultan Zainal Abidin, Malaysia. } \\
\text { Email: syadiah@unisza.edu.my }\end{array}$} \\
\hline
\end{tabular}

\section{INTRODUCTION}

The concept of gamification isn't new to the world now. It is because it has been used in many applications nowadays. The idea of gamification is using game design elements in non-game context to motivate and increase user engagement to gain knowledge or completion of certain tasks. The term gamification can be defined as the use of game design elements in non-game contexts [1]. It uses the competitive instinct possessed by most people to motivate and encourage the performance of people. The same concept of gamification can also be used to motivate and encourage collaborative and cooperative behavior similar to a competition between football clubs in a league.

The problems of education nowadays are that it is related to the lack of involvement and motivation of students to participate more actively during the learning process. According to the previous study by Gabe Zichermann [2], the use of game elements improves a user's capabilities to learn new skills by $40 \%$. By applying the engagement of players with game experience can be translated into the educational context to facilitate learning and to influence the behavior of students. This approach leads to higher level of commitment and motivation of users to activities and processes in which they are involved. Since players much enjoy spending countless of hours to play games, this motivation should be applied to the classroom [3].

A learning management system (LMS) is a software application or web-based application used for administering, tracking, reporting and delivering educational courses or training programs. It is widely used in an educational institution such as schools, universities, and colleges. The recent version of LMS applied many gamification elements to influence behavior as well as to improve motivation and engagement during learning process [4]. A study conducted by Traci Sitzmann found that students scored $14 \%$ higher using a gamified approach in a course on a subject than those who took a traditional course [5]. With gamified 
learning management system, it can facilitate the learning process as we can improve student motivation and enhance their engagement while tracking their progress.

LINUS is the literacy and numeracy screening that started in 2010 till now for students with special needs. Literacy is the ability to read, write easy compound sentences using conjunctions and apply the knowledge for daily learning and communication. While numeracy is the ability to perform basic mathematical operations as well as understand simple mathematical ideas and apply the knowledge and mathematical skills in daily life [6]. This program is intended to ensure that all students from standard one is able to master the basics of reading, writing and counting at the end of standard three [7].

\section{CONCEPTUAL FRAMEWORK OF GLMS FOR LINUS STUDENTS}

This framework was developed to guide the development of the Gamified Learning Management System for LINUS Students, as shown in Figure 1. The combination of gamification elements mechanisms, multimedia elements as well as learning theories are aimed at enabling more effective learning process for LINUS students.

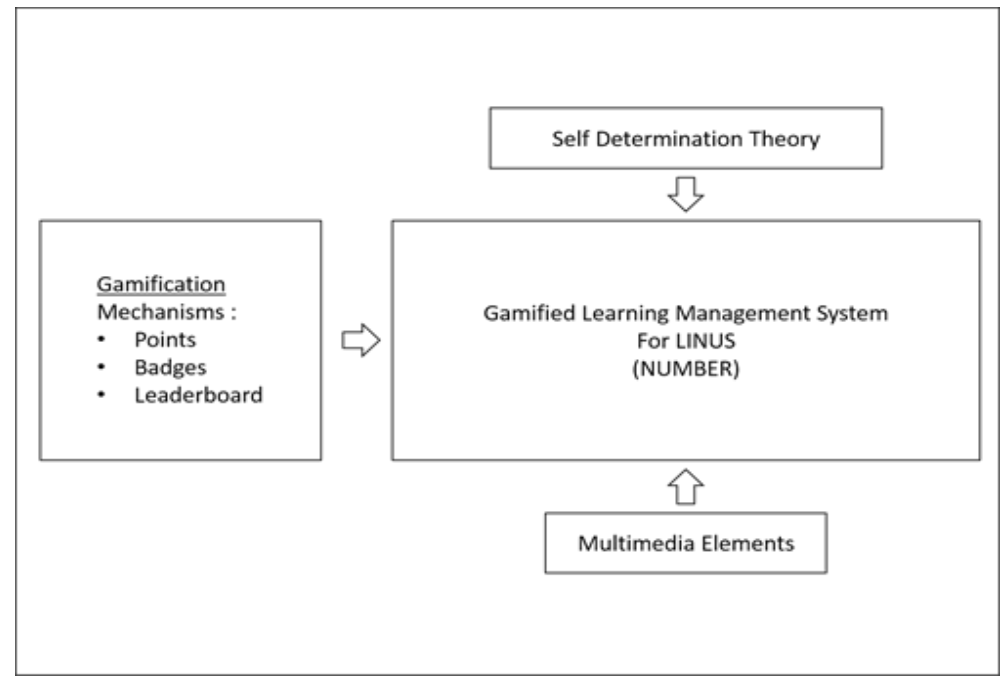

Figure 1. The Conceptual Framework of Gamified Learning Management System for LINUS Students

\section{GAMIFICATION ELEMENTS}

Gamification is defined as the use of game design elements in non-game contexts [1]. The purpose of gamification is to increase motivation through engagement. The most frequently used game mechanisms are points, badges, and leaderboards [8]. Points, badges, and leaderboards are common gamification elements that are making their way into educational practice [9]. For example, students can compete with others, or with a self-imposed goal to gain more knowledge and the additional reputation of a series of badges while they learn. Digital badges can be part of score keeping for educational journeys. Studies show that by using gamification most of the students are motivated to work on their learning outcomes [9], [10].

\subsection{Points}

Points are numerical values that define a method of feedback to users. They show how they are progressing in the game. Users are motivated when they are progressively being rewarded for their performance in a game [11]. In this system, points will be calculated from the score that will be taken from each task and test the student takes. Then the points will be saved in the student's profile.

\subsection{Badges}

Badges refer to trophies that represent virtual achievements awarded to the user that signify recognitions and accomplishments of certain tasks. At the time when achievements were included as game elements in Xbox Live Platform [12], there was a huge scale usage of badges in online games. Since then, badges have been widely implemented on other gaming platforms and have shown a high degree of achievement, which then contribute to higher sales profits and higher scores in reviews [13]. A report from previous researches shows that most of the students are motivated to participate in the activity [10].

A Conceptual Framework for Gamified Learning Management System... (Syadiah Nor Wan Shamsuddin) 
As described by the function, it will be used as a reward when users accomplish certain tasks. Badges are often used to encourage early participation and task completion and it is used only for nonlinear progress.

\subsection{Leaderboards}

A report from previous researches shows that most of the students are motivated to participate in the activity by using leaderboards in the learning process [10]. The leaderboards display the individual's performance in comparison to other users. The table lists the users in the order of points they collected in the game. By showing their points relative to what other users accomplished, the user may strive to accomplish the task [14]. For the system, we will introduce the leaderboards to the students and let the students know that a leaderboard would be displayed for each of the assignments in the learning management system. The system manage these assignments and tracke students' accomplishment of these assignments and their points for each assignment. Once the assignments are marked and the points are calculated, the leaderboards will be updated by the system and ready to be displayed to the students. It can motivate users as they are able to compare their points with others.

\section{MULTIMEDIA ELEMENTS}

Multimedia elements is a very powerful module for any kind of presentation interface nowadays. These elements help facilitate the learning process and has become increasingly prevalent in educational setting [15]. The components of multimedia consist of a combination of text, audio, images, drawings, animation, video, and interactivity [16], [17]. These elements give significant impact in assisting the teaching and learning process. The use of graphics can help to attract and motivate as well as improve memories of learners [18]. A multimedia application may require audio or sound to attract learners [19]. The purpose of using form text is to give effect to the perceptions and to highlight the importance of an information to the users [20]. The use of text in the development of this system is to give instruction and information to users such as student profiles, points, reports, and more. Images and illustrations are also used as instruction and information graphically such as student image, badges, icon, and more. The hyperlink is used in this system as an icon, graphic or text in the system that links to another file or object.

\section{LEARNING THEORIES}

Motivational theory needs to be applied during the application development as teaching and learning guidelines. It will allow the use of limited sources to be more effective. The theory that will be considered in the development of the system design is Self-Determination Theory.

\subsection{Self Determination Theory}

Self-Determination Theory (SDT) is a theory of motivation. It is concerned with supporting our intrinsic tendencies to behave in effective ways. SDT has been practiced by many researchers around the globe for applications such as education, healthcare, sports and exercise, organization, and more. SelfDetermination Theory refers the suggestion that all humans are motivated by a drive to self-determine a path of life for themselves. This is done by meeting three needs: feeling competent in the tasks you attempt [21], feeling that you have accomplished those tasks without the influence of others [21], [22], and feeling that your life is connected to those around you [21]. SDT defines two types of concepts of motivation that are intrinsic, which refers to those three needs, and extrinsic, which is a motivation that is influenced by external sources such as fame, money, grades, and praise. A report from previous researchers in SDT has shown that intrinsic and extrinsic motivations work together. The intrinsic occurs when tasks have been internalized, whereas extrinsic is most suitable to use to get people to try new tasks [23]. SDT can be used to introduce a person to something they don't have any practical knowledge yet so that they develop intrinsic motivation later. Based on the self-determination theory, we suggest that meaningful gamification design should have three basic properties: feeling that you have accomplished those tasks without the influence of others, feeling competent in the tasks you attempt, and feeling that your life is connected to those around you. Thus, this theory is suitable to encourage motivation and engagement during the learning process.

\section{RESULT AND DISCUSSION}

The main finding of this research is a conceptual framework for designing Gamified Learning Management System for LINUS students. The proposed conceptual framework will be validated using prototyping approach. 
In summary, by adapting the theories, literature review, the conceptual framework proposed were applied in the development phase. The system is used by teaching teachers. Teachers will show student progress and their position in leaderboards based on the points and badges regularly before each class begins. It can motivate users as they are able to compare their points with others.

Figure 2 and 3 show user interface of registration and login. Users need to register with the system before they can login into the system.

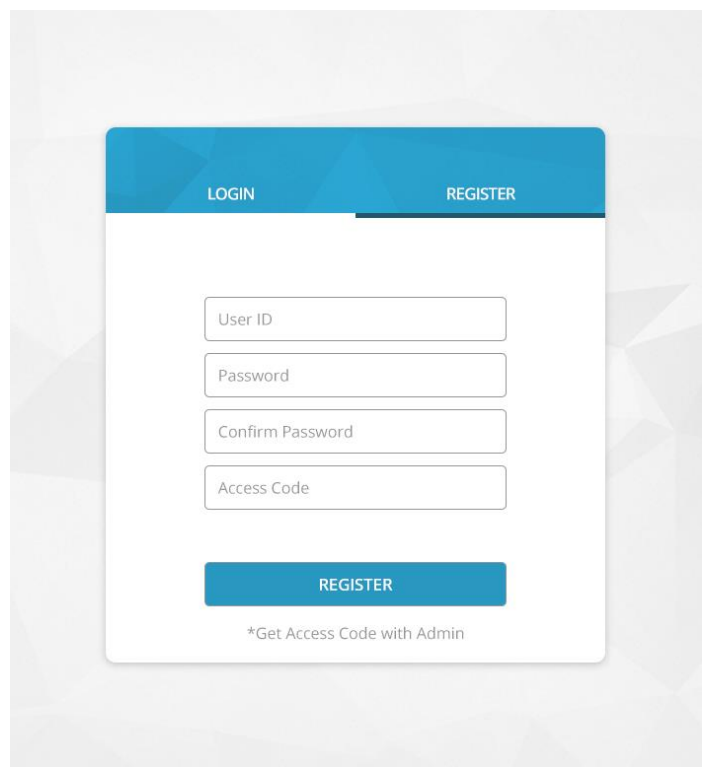

Figure 2. User interface of user registration

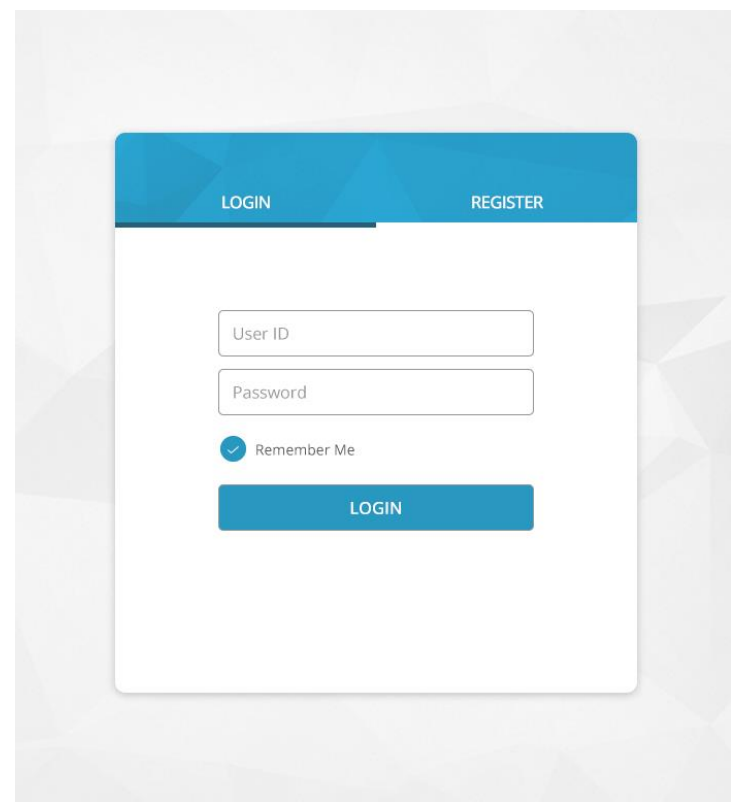

Figure 3. User interface of user $\log$ in

Students can view their profile and progress on the student report as shown in Figure 4 and 5. They can view the badge they have earned and their position in the class. The self-determination theory are applied on this page. With this summary report, students can create new targets to earn other available badges and points. This will indirectly increase their enthusiasm for learning. 
Gamification elements are applied to GLMS. Leaderboards are used to display the individual's performance compared to other users. In the leaderboard there are information about students which is, points and number of badges they earned as shown in Figure 6.

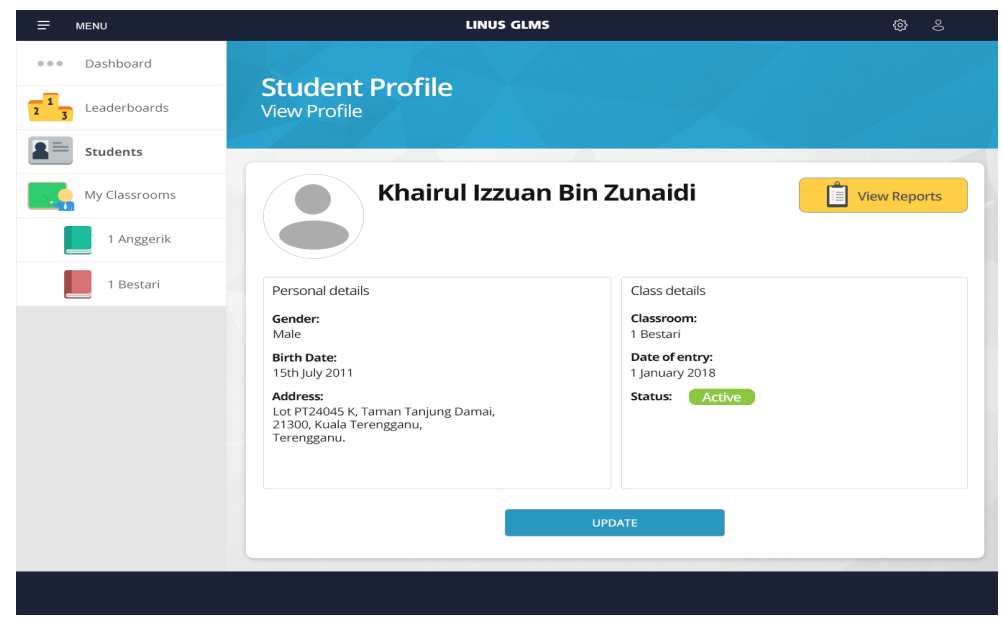

Figure 4. User interface of student profile

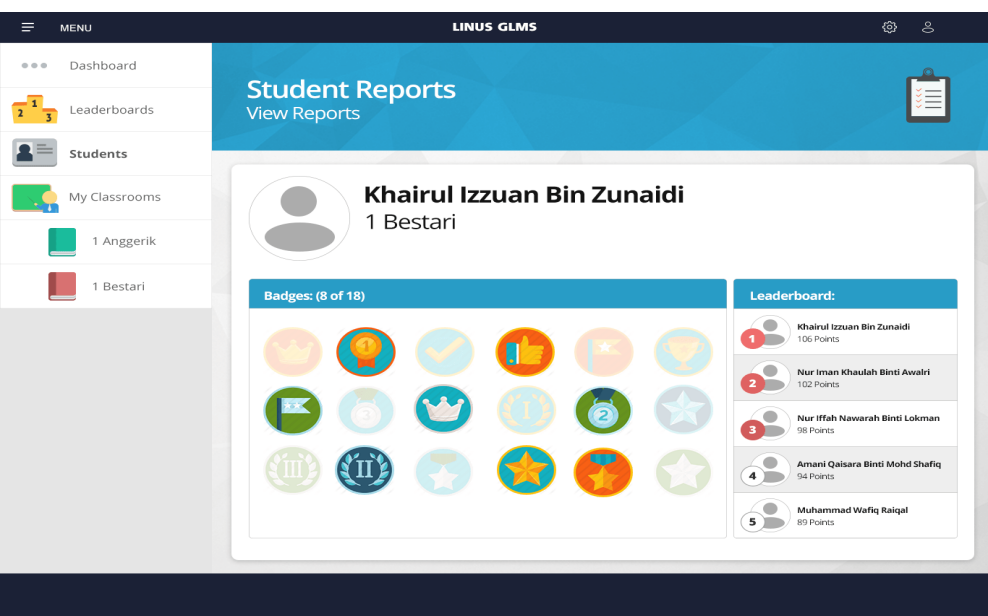

Figure 5. User interface of student reports

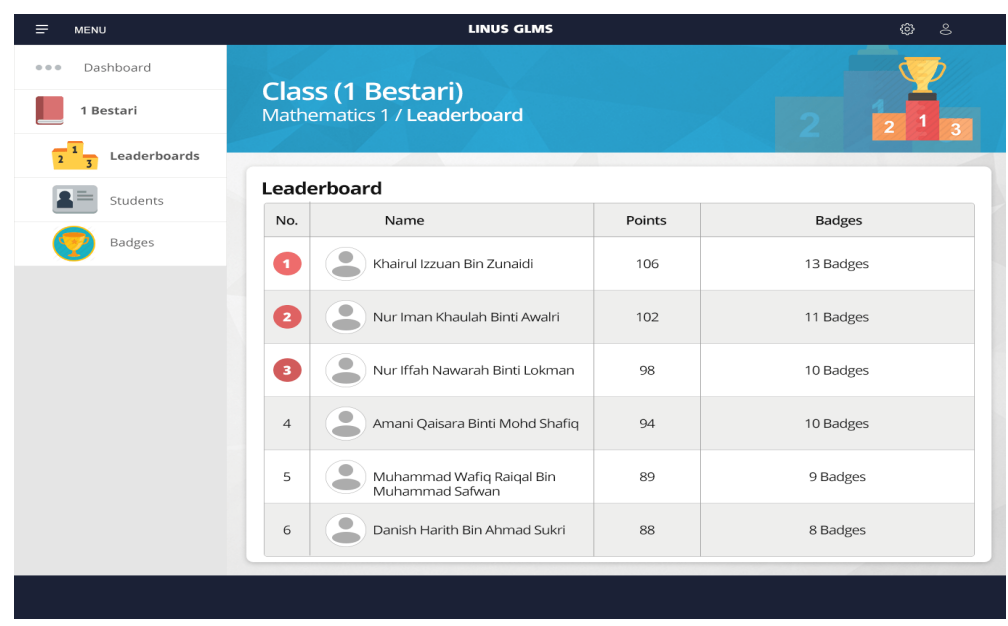

Figure 6. User interface of leaderboard of mathematics 1 


\section{CONCLUSION}

This research will create the fundamental components in developing the Gamified Learning Management System for LINUS Students. It is hoped that through this method, it can provide a more enjoyable learning technique for the users as well as to assist the learning process in future.

\section{ACKNOWLEDGEMENT}

The authors would like to express their gratitude to the Faculty of Informatics and Computing, Universiti of Sultan Zainal Abidin (UniSZA) for the support and facilities provided.

\section{REFERENCES}

[1] Deterding, S., Dixon, D., Khaled, R., \& Nacke, L. From game design elements to gamefulness: defining gamification. In Proceedings of the 15th International Academic MindTrek Conference: Envisioning Future Media Environments. Tampere. 2011: 9-15.

[2] Giang, V. “Gamification” Techniques Increase Your Employees' Ability to Learn By 40\%. 2013. Retrieved from Business Insider: http://www.businessinsider.com/gamification-techniques-increase-your-employees-ability-tolearn-by-40-2013-9/?IR=T/.

[3] Leaning, M. A study of the use of games and gamification to enhance student engagement, experience and achievement on a theory-based course of an undergraduate media degree. Journal of Media Practice. 2015; 16(2): $155-170$.

[4] Swacha J. An Architecture of a Gamified Learning Management System. International Conference on Web-Based Learning. Tallin. 2014. 195-203.

[5] Sitzmann, T. A Meta-Analytic Examination of the Instructional Effectiveness of Computer-Based Simulation Games. Personnel Psychology. 2011. 64(2): 489-528.

[6] Ministry of Education Malaysia. Garis panduan pentadbiran saringan linus pendidikan khas. Putrajaya: Ministry of Education Malaysia. 2016: 1-3.

[7] Rifke, A. NKRA Kementerian Pendidikan Malaysia untuk Linus NKRA \& SAPS NKRA. 2017. https://www.sistemguruonline.my/2017/04/linus-nkra-saps-nkra.html.

[8] Dicheva, D., Dichev, C., Agre, G., \& Angelova, G. Gamification in Education: A Systematic Mapping Study. Educational Technology \& Society. 2015. 18(3): 75-88.

[9] Gibson, D., Ostashewski, N., Flintoff, K., Grant, S. \& Knight, E. Digital Badges in Education. Education and Information Technologies. 2015. 20(2): 403-410.

[10] Huang, B., \& Hew, K. F. Do points, badges and leaderboard increase learning and activity: A quasi-experiment on the effects of gamification. Proceedings of the 23rd International Conference on Computers in Education. 2015: 275 280. China: Asia Pacific: Society for Computer in Education.

[11] Nah, F.F.-H., Zeng, Q., Telaprolu, V.R., Ayyappa, A.P., Eschenbrenner, B. Gamification of education: a review of literature. In: Nah, F.F.-H. (ed.) HCIB 2014. LNCS, vol. 8527. Springer, Heidelberg. 2014: 401-409.

[12] Jakobsson, M. The achievement machine: understanding xbox achievements in gaming practices. International journal of computer game research. 2011. 11(1).

[13] Electronic Entertainment Design and Research. EEDAR Study Shows More Achievements in Games Leads to Higher Review Scores, Increased Sales. Press 2007. https://www.businesswire.com/news/home/20071016005432/en/EEDAR-Study-Shows-Achievements-GamesLeads-Higher.

[14] Galli, L., Fraternali, Piero, Bozzon, Alessandro. On the application of game mechanics in information retrieval. Proceedings of the First International Workshop on Gamification for Information Retrieval. 2014: 7-11.

[15] Fenesi, B. Multimedia design \& cognitive learning theory. McMaster University. 2011.

[16] Zhang S, Shi W, Liu Z, Hu Q. The principles of multimedia teaching design based on cognitive load theory. Education Technology and Computer (ICETC), 2010 2nd International Conference on. 2010; 3(3): 110-112.

[17] Weiss, I., Kramarski, B., Talis, S. Effects of multimedia environments on kindergarten children's mathematical achievements and style of learning. Educational Media International. 2007; 43(1): 3-17.

[18] Betrancourt, M., Chassot, A. Making Sense of Animation. Learning with Animations: Research Implications for Design. 2008: 141-64.

[19] Ali B, Zaman HB. Framework for adaptive multimedia mathematics courseware. In Proceedings of the 2nd IMTGT Regional Conference on Mathematics, Statistics and Applications. Penang 2006: 13-15.

[20] Hoffer, J.A., George, J.F., Valacich, J.S. Modern Systems Analysis and Design, Sixth Edition, New Jersey: Prentice Hall, 2011.

[21] Ryan, R. M., \& Deci, E. L. Intrinsic and Extrinsic Motivations: Classic Definitions and New Directions. Contemporary Educational Psychology, 2000; 25(1): 54-67.

[22] De Charms, R. Personal causation: The internal affective determinants of behavior. New York, NY: Academic Press. 1968.

[23] Edward L. Deci \& Richard M. Ryan. The "What" and "Why" of Goal Pursuits: Human Needs and the SelfDetermination of Behavior, Psychological Inquiry: An International Journal for the Advancement of Psychological Theory. 2000; 11(4): 227. 